\title{
A demographic profile of patients seeking MTP for gross congenital malformations in a tertiary referral hospital in North India
}

\author{
Shaveta Jain ${ }^{1}$, Vandana Rani ${ }^{1}$, Roopa Sangwan ${ }^{1}$, Nitin Jain ${ }^{2 *}$ \\ ${ }^{1}$ Department of Obstetrics and Gynecology, Pt. B. D. Sharma, PGIMS, University of Health Sciences, Rohtak, \\ Haryana, India \\ ${ }^{2}$ Department of Radiology, Advanta Super Specialty Hospital and Trauma Center, Rohtak, Haryana, India
}

Received: 4 September 2018

Accepted: 28 September 2018

\section{*Correspondence:}

Dr. Nitin Jain,

E-mail: logindrnitin@gmail.com

Copyright: $\odot$ the author(s), publisher and licensee Medip Academy. This is an open-access article distributed under the terms of the Creative Commons Attribution Non-Commercial License, which permits unrestricted non-commercial use, distribution, and reproduction in any medium, provided the original work is properly cited.

\section{ABSTRACT}

Background: The objective of the study was to study the sociodemographic, obstetrics profile and folic acid intake in women seeking medical termination of pregnancy for gross congenital malformed fetus (GCMF)and to study pattern of GCMF.

Methods: A cross sectional study was conducted among women who underwent medical termination of pregnancy for congenital malformation in fetus in tertiary referral hospital of north India. The details regarding their sociodemographic profile, previous obstetrics history, pattern of GCMF, history of folic acid intake and method of termination were taken.

Results: $61 \%$ of women seeking medical termination of pregnancy for GCMF were of age group 20-25 years. 75 women were from rural area which is $83.3 \%$ in present study. Only $13.3 \%$ of women in present study were illiterate. Most of the women $66.6 \%$ belongs to middle class of society in present study. $40 \%$ women seeking medical termination of pregnancy for congenital anomaly were primigravida. $96.6 \%$ of patient's congenital anomaly was detected in second trimester. $74.4 \%$ of patient had central nervous system (CNS) congenital anomaly, most common was anencephaly in 34 patients followed by meningocele/myelomeningoceles in 9 fetuses. Only $27 \%$ women had history of folic acid intake and 55 patients were given mifepristone $200 \mathrm{mg}$ with $400 \mathrm{mcg}$ misoprostol while 32 patients who had previous history of cesarean section were given lower doses.

Conclusions: Anencephaly was the most common congenital anomaly detected. The high reporting of anencephaly suggests the need for a fortification of folic acid in food. Dismal rate of cardiac malformation suggests there is need of inclusion of cardiac echo in level II anomaly scan. Prolonged induction to abortion time in present study shows need of further studies for simultaneous or 24-hour regimen of mifepristone and misoprostol and higher doses of misoprostol.

Keywords: Folic acid, Gross congenital malformed fetus, Medical termination of pregnancy, Mifepristone, Misoprostol

\section{INTRODUCTION}

India is among the few countries which understand the importance of medical termination of pregnancy (MTP), law for which was made in as early as $1971 .{ }^{1}$ This law states that if there is a substantial risk of the child born with physical or mental abnormalities it could be terminated up to gestational age 20 weeks, as it reduces patient mental agony of carrying anomalous fetus to term. Congenital malformations have been known since long time. In the past congenital anomalies were detected after birth of fetus but now a days with advancement of 
ultrasound and increase in awareness about various diagnostic methods most anomalies are detected in utero.

The etiology of congenital malformation can be attributed to genetic $(32-40 \%)$, environment $(5-10 \%)$ however in $50 \%$ of the cases the cause is unknown. ${ }^{2}$ Global estimates suggest that congenital anomalies affect 2-3\% of births. ${ }^{2}$ Assuming a $2 \%$ birth prevalence, and 25,595,000 births in 2013, an estimated 511,900 births may have been affected with a congenital anomaly in India. ${ }^{3}$

In 2010, congenital anomalies were estimated to be the fifth largest cause of neonatal deaths in India after preterm births $(34.7 \%)$, intrapartum complications (19.6\%), pneumonia (16.3\%) and neonatal sepsis $(15 \%){ }^{2}$ Despite this ranking, in absolute numbers, congenital anomalies were estimated to contribute to 60,699 neonatal deaths in India in 2013, which accounted for the highest global burden of neonatal mortality due to congenital anomalies. ${ }^{3}$

The true magnitude of the number of births affected by congenital anomalies in India is unknown due to lack of a national birth defects surveillance. The need for data arises as currently there is no data on the impact of congenital anomaly affected pregnancies or births on health service utilization, for termination of pregnancy due to detection of a fetal anomaly. ${ }^{3}$

It is noteworthy that several studies have attempted to measure the magnitude of congenital anomalies in India. 4-6 However all studies had recorded congenital malformation on birth, none had studied congenital malformation diagnosed in utero and undergone medical termination of pregnancy.

The objective of the study was to study the sociodemographic, obstetrics profile, history of folic acid intake and termination methods in patient seeking medical termination of pregnancy for gross congenital malformed fetus (GCMF).

\section{METHODS}

A cross sectional study was conducted among women who underwent medical termination of pregnancy for congenital malformation of fetus in our hospital. The study was conducted from Jan 2017-Jan 2018 at department of obstetrics and gynecology of Pt. B. D. Sharma, PGIMS, Rohtak, Haryana, a tertiary referral 1600 bedded hospital. Currently it caters around 70-80 antenatal registration per day and 900-1000 deliveries per month.

\section{Inclusion criteria}

Authors included in present study all women diagnosed with gross congenital malformed fetus on ultrasound and having gestational age less than 20 weeks.

\section{Exclusion criteria}

Women having gestation more than 20 weeks, allergic to drugs, asthmatic and having acute renal or adrenal disease were excluded from present study.

The details regarding their sociodemographic profile (age, residence, education), previous obstetric history (estimated period of gestation), pattern of GCMF, history of folic acid intake and method of termination were taken. Diagnosis of congenital malformation was confirmed by a ultrasonographic examination by radiologist at our hospital.

\section{RESULTS}

During the study period, 968 women sought termination of pregnancy. 861 underwent medical termination and surgical method required in 107 women Out of these. 751 women presented for termination of pregnancy during first trimester. Only 3 medical termination of pregnancy were done for GCMF during this period.

Table 1: Demographic profile of patients seeking MTP for GCMF.

\begin{tabular}{|lll|}
\hline \multicolumn{2}{|c|}{ Frequency } & Percentage \\
\hline Age groups (years) & & \\
\hline $15-20$ & 10 & 11 \\
\hline $20-25$ & 55 & 61 \\
\hline $25-30$ & 22 & 24 \\
\hline$>30$ & 3 & 3 \\
\hline Place of residence & & \\
\hline Rural & 75 & 83.3 \\
\hline Urban & 15 & 16.7 \\
\hline Educational status & & \\
\hline Illiterate & 12 & 13.3 \\
\hline Up to matric & 35 & 38.8 \\
\hline Up to graduate & 30 & 33.3 \\
\hline Postgraduate & 13 & 14.4 \\
\hline Socioeconomic class & & \\
\hline Upper class & 06 & 6.6 \\
\hline Upper middle class & 24 & 26.6 \\
\hline Middle class & 36 & 40 \\
\hline Lower middle class & 14 & 15.5 \\
\hline Lower class & 10 & 11.1 \\
\hline
\end{tabular}

110 women reported during their second trimester, out of which in 87 women the cause for termination of pregnancy GCMF. $61 \%$ of women seeking medical termination of pregnancy for GCMF were of age group 20-25 years (Table 1).

Mean age was 25 years with range 19-38 years. 75 women were from rural area which is $83.3 \%$ in present study (Table 1). Only $13.3 \%$ of women in present study were illiterate. Most of the women (66.6\%) belong to middle socioeconomic class in present study (Table 1). 
$40 \%$ women seeking medical termination of pregnancy for congenital anomaly were primigravida (Table 2). In $96.6 \%$ of patient's congenital anomaly was detected in second trimester (Table 2). 54.4\% were from 17-19 weeks gestation. $35.6 \%$ patient had previous history of cesarean section (Table 2).

Table 2: Obstetrics history of patients.

\begin{tabular}{|c|c|c|}
\hline & Frequency & Percentage \\
\hline \multicolumn{3}{|l|}{ Gravida } \\
\hline G1 & 36 & 40 \\
\hline $\mathrm{G} 2$ & 25 & 27.7 \\
\hline $\mathrm{G}=3>3$ & 29 & 32.2 \\
\hline Trimester & $\mathrm{F}$ & \\
\hline First trimester ( $<12$ weeks) & 3 & 3.33 \\
\hline $\begin{array}{l}\text { Second trimester }(12-20 \\
\text { weeks) }\end{array}$ & 87 & 96.66 \\
\hline \multicolumn{3}{|c|}{ Gestational age on admission } \\
\hline $11-13$ & 3 & 3.3 \\
\hline $13-15$ & 16 & 17.7 \\
\hline $15-17$ & 16 & 17.7 \\
\hline $17-19$ & 49 & 54.4 \\
\hline $19-21$ & 3 & 3.33 \\
\hline \multicolumn{3}{|l|}{ H/O Previous cesarean } \\
\hline Previous LSCS & 22 & 24.4 \\
\hline Previous 2 LSCS & 10 & 11.1 \\
\hline
\end{tabular}

Types of gross congenital malformation are shown in Table 3. $74.4 \%$ of patient had central nervous system (CNS) congenital anomaly (Table 3), most common was anencephaly in 34 patients followed by meningocele/ myelomeningoceles in 9 fetuses.

Only 5 cases of cardiovascular system anomaly were detected with left hypoplastic heart in 2 patients. 4 women had fetus with genitourinary tract anomaly while 5 women had fetus with gastrointestinal tract malformation.

Musculoskeletal abnormality was seen in 5 patients while 4 women having fetus with multiple abnormality on sonography (Table 3).

Only $27 \%$ women had history of folic acid intake and only 2 women had history of folic acid intake in preconception period (Table 4).

The regimen for termination of pregnancy in all patients was mifepristone followed by misoprostol (Table 5). 55 patients were given mifepristone $200 \mathrm{mg}$ followed by 400 mcg misoprostol. 32 patients who had previous history of cesarean section were given lower doses of $200 \mathrm{mcg}$ misoprostol.

The dose of misoprostol was adjusted to lower dose in women with history of previous cesarean section (Table 5). Most patient delivered in 36-48 hours.
Table 3: Gross congenital malformation seen in fetuses.

\begin{tabular}{|c|c|c|}
\hline GCMF & Frequency & $\%$ \\
\hline CNS & 67 & 74.4 \\
\hline GIT & 5 & 5.5 \\
\hline GUT & 4 & 4.4 \\
\hline CVS & 5 & 5.5 \\
\hline Musculoskeletal & 5 & 5.5 \\
\hline Multiple organ involvement & 4 & 4.4 \\
\hline CNS Anomaly & \multicolumn{2}{|l|}{ No. of cases } \\
\hline Anencephaly & \multicolumn{2}{|l|}{34} \\
\hline $\begin{array}{l}\text { Meningeocele/ } \\
\text { meningeomyelocele }\end{array}$ & \multicolumn{2}{|l|}{9} \\
\hline Holoporencephaly & \multicolumn{2}{|l|}{5} \\
\hline $\begin{array}{l}\text { Hyderocephalus with arnold } \\
\text { chiari malformation }\end{array}$ & \multicolumn{2}{|l|}{6} \\
\hline Spinal dysraphism & \multicolumn{2}{|l|}{6} \\
\hline Diastometamylia & \multicolumn{2}{|l|}{1} \\
\hline $\begin{array}{l}\text { Exencephaly/ inencephaly/ } \\
\text { acrania }\end{array}$ & \multicolumn{2}{|l|}{4} \\
\hline Dandy walker syndrome & \multicolumn{2}{|l|}{2} \\
\hline \multicolumn{3}{|l|}{ CVS } \\
\hline Hypoplastic left ventricle & \multicolumn{2}{|l|}{2} \\
\hline PS & \multicolumn{2}{|l|}{1} \\
\hline TOF & \multicolumn{2}{|l|}{1} \\
\hline $\begin{array}{l}\text { Transposition of great } \\
\text { arteries }\end{array}$ & \multicolumn{2}{|l|}{1} \\
\hline \multicolumn{3}{|l|}{ Renal anamolies } \\
\hline $\begin{array}{l}\text { Multicystic dysplastic } \\
\text { kidney }\end{array}$ & \multicolumn{2}{|l|}{2} \\
\hline Fetal megacystitis & \multicolumn{2}{|l|}{1} \\
\hline $\mathrm{B} / \mathrm{l}$ Renal agenesis & \multicolumn{2}{|l|}{1} \\
\hline \multicolumn{3}{|l|}{ Git anamolies } \\
\hline Omphalocele & \multicolumn{2}{|l|}{4} \\
\hline Abdominal cyst & \multicolumn{2}{|l|}{1} \\
\hline \multicolumn{3}{|l|}{ Musculoskeleton anamolies } \\
\hline $\begin{array}{l}\text { Short limbs (thanotrophic } \\
\text { dysplasia) }\end{array}$ & \multicolumn{2}{|l|}{3} \\
\hline Osteogenesis imperfecta & \multicolumn{2}{|l|}{2} \\
\hline Multiple organs (Vectral) & \multicolumn{2}{|l|}{2} \\
\hline Down syndrome & \multicolumn{2}{|l|}{2} \\
\hline
\end{tabular}

Table 4: Patients having history of folic acid intake.

\begin{tabular}{|lll|}
\hline H/o of folic acid intake & Frequency & Percentage \\
\hline Primigravida & 10 & 27 \\
\hline Multigravida & 30 & 55 \\
\hline
\end{tabular}

\section{DISCUSSION}

Mean age of women in present study was 25 years which was younger than other study conducted outside India. It may be due to younger age of marriage in our country. ${ }^{7}$ Dhillion et al in their study in 13 states of India found that three-fifths of the induced abortion seekers were between $25-34$ years. $^{8}$ 
In present study, $97 \%$ patient were younger than 30 years. This is since although chances of congenital anomaly increase with maternal age, number of pregnancies in early age outnumber pregnancies in late age. There was no history of consanguineous marriage in any women, while study done by Samadirad et al showed $35 \%$ consanguineous marriage in patient having congenital malformed fetus, due to cultural difference. ${ }^{7}$

Most of the patients were from rural background, while Gupta $\mathrm{S}$ et al study showed that $46 \%$ patient were from urban slums. this is because ours is a government hospital which is catering maximum patients from rural area. ${ }^{9}$ In present study, $97 \%$ of the congenital anomalies were detected during second trimester while Namrata et al in her retrospective observation study found that first trimester ultrasound could have identified $50 \%$ of major structural defects compared to $1.6 \%$ in the present scenario as most of women report in early second trimester and thus they were advised anomaly scan late in pregnancy, secondly, they come to us after visiting different hospitals. ${ }^{10}$

Table 5: Medical termination of pregnancy.

\begin{tabular}{|lll|}
\hline Treatment & Mifeprestone $(200 \mathrm{mg})+$ misoprostol $800 \mathrm{ug}$ & 3 \\
\hline Up to 12 weeks & Frequency \\
\hline 12-20 weeks without h/o previous LSCS & Mifepristone $(200 \mathrm{mg})+$ misoprostol 400 ug repeated 4-6 hourly & 55 \\
\hline 12-20 weeks with history of LSCS & $\begin{array}{l}\text { Mifepristone }(200 \mathrm{mg})+\text { misoprostol 400 ug followed by } \\
\text { misoprostol 200 ug repeated 4-6 hourly }\end{array}$ & 32 \\
\hline
\end{tabular}

86.7 percent of our patients were literate, while $55 \%$ patients in study by Gupta $\mathrm{S}$ et al were illiterate, it is due to better female literacy rate in our state. Most of the patients in present study belongs to middle class while in other study $9=$ most women belonged to lower socioeconomic status, this is due to higher per capita income of our state, Haryana. ${ }^{9,11}$

CNS were leading congenital abnormality seen in women patient seeking medical termination of pregnancy, while other studies showed cardiac defects as most common, this difference is because these studies were done on birth, so congenital abnormalities seen in their study were those which are correctable and compatible with life. ${ }^{12}$

Neural tube defect, anencephaly was most common CNS anomaly in women seeking medical termination, though during last decade critical association had been established between lack of folate and neural tube defect however there is no awareness among general population about intake of folate during pregnancy.

In present study only $30 \%$ of primigravida patient were taking folate. Such dismal rates of folate intake may be due to the fact that majority of pregnancies in India are not planned and one the dichotomy is that female realize their pregnancy after 3rd week of conception. when folic acid supplement even consumed will be too late as neural tube closes by 27 days.

There is need of food supplementation as done in developed countries as incidence of NTD in India is 3 times more than developed countries. Bhide et al calculated deficiency in 584 women in early pregnancy, folate deficiency was detected in $24 \%$ women and possible deficiency in $21 \% .^{13}$ In present study multigravida show better folate intake then primigravida as multigravida have knowledge of folate intake, but it was not significant which shows that perhaps patient had folate in previous pregnancy but was not informed why folate is given to her, so obstetrician must sensitize patients about importance of folate during first trimester. In study done by Bhide et al, congenital heart defects (CHDs) were the most prevalent anomalies (65.86 per 10 000 births), with atrial septal defects (43.91 per 10000 births) and ventricular septal defects (27.44 per 10000 births) being the most commonly presenting heart defects. Two-thirds of the CHDs were detected post birth at mean age $4.5 \pm 2$ days. $^{12}$

Only 5 patients come for medical termination of pregnancy for cardiac malformation in present study it is because the cardiac anomaly like ventricular septal defect (VSD) and atrial septal defect (ASD) are compatible with life and patient are not advised to seek medical termination of pregnancy for such congenital anomaly and Fetal echo is needed for detection of cardiac anomaly which is not part of level II (anomaly scan) ultrasound in our hospital.

Authors have only 5 cases of musculoskeletal abnormities while other study has higher number on birth because in their study talipes equinovarus was most common which is easily correctable patient do not seek medical termination for them.

Authors use mifepristone and misoprostol for medical termination. ACOG practice bulletin on medical termination of pregnancy for second trimester, higher doses of $800 \mathrm{mcg}$ of misoprostol were used however at our institute management depends upon h/o previous LSCS we used lower dose of misoprostol $400 \mathrm{mcg}$ if 
history of previous one LSCS due to fear of scar dehiscence. ${ }^{14}$ Most of our patients delivered in 36-48 hours, induction to abortion time was higher in our patients as we used low dose of misoprostol to prevent side effects seen on higher doses. None of the patient required hysterotomy. Main limitation of the study was that no, autopsy examination, karyotyping, biochemical were not undertaken due to resource constraint.

\section{CONCLUSION}

The main scope of this study was to study demographic profile of women seeking medical termination for major congenital malformation in utero. Most women, $61 \%$ were of younger age group, $87.5 \%$ were literate and $66 \%$ were from middle class. Almost all termination for congenital anomaly were done in second trimester. It throws light on the importance of screening as well as an immense need for early diagnosis in the field of prenatal detection of congenital malformation.

Anencephaly was the most common congenital anomaly detected. The high reporting of anencephaly suggests the need for a preconception folic acid supplementation program and fortification of food with folic acid. Dismal rate of cardiac malformation suggests there is need of inclusion of cardiac echo in level II anomaly scan. Prolonged induction to abortion time in present study shows need of further studies for simultaneous or 24-hour regimen of mifepristone and misoprostol and higher doses of misoprostol.

\section{Funding: No funding sources}

Conflict of interest: None declared

Ethical approval: The study was approved by the Institutional Ethics Committee

\section{REFERENCES}

1. Ministry of Health and Family Welfare. (10 August 1971) the Medical Termination of Pregnancy Act 1971, Delhi: Government of India

2. Liu L, Johnson HL, Cousens S, Perin J, Scott S, Lawn JE, et al. Global, regional, and national causes of child mortality: an updated systematic analysis for 2010 with time trends since 2000. The Lancet. 2012;379(9832):2151-61.

3. Liu L, Oza S, Hogan D, Perin J, Rudan I, Lawn JE, et al. Global, regional, and national causes of child mortality in 2000-13, with projections to inform post2015 priorities: an updated systematic analysis Lancet. 2015;385(9966):430-40.

4. Agarwal SS, Singh U, Singh PS, Singh SS, Das V, Sharma A et al. Prevalence and spectrum of congenital malformations in a prospective study at a teaching hospital. Indian J Med Res. 1991;94:413-9.

5. Baruah J, Kusre G, Bora R. Pattern of gross congenital malformations in a tertiary referral hospital in Northeast India. Ind J Pediatrics. 2015;82(10):917-22.

6. Sachdeva S, Nanda S, Bhalla K, Sachadeva R. Gross congenital malformation at birth in a government hospital. Indian J Public Health. 2014;58(1):54-6.

7. Samadirad B, Khamnian Z, Hosseini MB, Dastgiri S. Congenital anomalies and termination of pregnancy in Iran. J Pregnancy. 2012; PMC3348644.

8. Dhillon BS, N. Chandhio, I. Kambo, and N.C. Saxena. "Induced abortion and concurrent adoption of contraception in the rural areas of India (an ICMR task force study)," Indian J Med Sci. 2004;58(11):478-84.

9. Gupta S, Dave V, Sochaliya K, Yadav S. A Study on socio-demographic and obstetric profile of MTP seekers at Guru Govind Singh Hospital, Jamnagar. Healthline. 2012;3(1):50-4

10. Kashyap N, Pradhan M, Singh N, Yadav S. Early detection of fetal malformation, a long distance yet to cover! present status and potential of first trimester ultrasonography in detection of fetal congenital malformation in a developing country: experience at a tertiary care centre in India. Journal of pregnancy. $2015 ; 2015$.

11. Singh T, Sharma S, Nagesh S. Socio-economic status scales updated for 2017 Int J Res Med Sci. 2017;5(7):3264-7

12. Bhide P, Gund P, Kar A (2016) Prevalence of Congenital Anomalies in an Indian Maternal Cohort: Healthcare, Prevention, and Surveillance Implications. PLoS ONE 11(11): e0166408.

13. Bhide P, Kar A. Prevalence and determinants of folate deficiency among urban Indian women in the periconception period. European journal of clinical nutrition. 2018 Jul 19:1.

14. American College of Obstetricians and Gynecologists. ACOG Practice Bulletin No. 135: Second-trimester abortion. Obstet Gynecol. 2013;121(6):1394-406.

Cite this article as: Jain S, Rani V, Sangwan R, Jain $\mathrm{N}$. A demographic profile of patients seeking MTP for gross congenital malformations in a tertiary referral hospital in North India. Int J Reprod Contracept Obstet Gynecol 2018;7:4465-9. 